\title{
How does being out at work relate to discrimination and unemployment of gays and lesbians?
}

\author{
Karel Fric ${ }^{*}$ (i)
}

\begin{abstract}
This article empirically investigates the relationships in the workplace between homonegativity, the disclosure of sexual orientation, perceived discrimination, the reporting of discriminatory incidents and an individual's employment status. I utilize information reported by gays and lesbians in the EU lesbian, gay, bisexual and transgender (LGBT) survey. The data was analysed using generalised structural equation modelling and the logistic regression model. The results indicate that gays and lesbians conceal their sexual orientation more in hostile workplaces. A higher level of concealment is linked with an increased perception of discrimination and with a lower likelihood of reporting discriminatory incidents. Perceived discrimination and (unlike hypothesised) also concealment of sexual orientation positively relate to the probability of being unemployed. This implies a vicious circle in which hostile attitudes force gay employees to conceal their sexuality which in turn limits their ability to confront discriminatory behaviour.
\end{abstract}

Keywords: Disclosure of sexual orientation, Discrimination, Homosexuality, LGBT, Unemployment

\section{Introduction}

There is extensive evidence that gays and lesbians face discrimination in the workplace (Eurofound 2016; Valfort 2017). Research review by Fric (2017) indicates that gay people ${ }^{1}$ face barriers when accessing employment. Recent surveys among gays and lesbians in Europe show that a considerable amount of respondents experienced discrimination or harassment in the workplace (Eurofound 2016). However, sexual orientation discrimination is rarely reported and scarcely results in court cases in Europe (van Balen et al. 2011). The lack of official cases may lead to the conclusion that discrimination against sexual minorities is not a common problem in the labour market. Such interpretation has implications for policies on this issue.

It is desirable to understand what the relationships are between (perceived) discrimination, the employment status and reporting of discrimination in gay people. Is perceived discrimination related to employment status? How does the perception of being discriminated at work relate

*Correspondence: karel.fric@gmail.com

Erasmus University Rotterdam, Rotterdam, The Netherlands to the reporting of discrimination incidents? How do disclosure of sexual orientation and sexual prejudice in the workplace influence these outcomes? In this article I try to answer these questions. I formulate several hypotheses that I empirically test using the European Union Lesbian, Gay, Bisexual and Transgender (EU LGBT) survey ${ }^{2}$ data. I applied structural equation model and verified the results with the logistic regression model.

I am not aware of any study that would empirically test the relationship between my concepts of interest. The research has concentrated on the antecedents of disclosure of sexual orientation in the workplace (such as company policies, extent of disclosure in other contexts) and the effects of disclosure (for example on employees' commitment, job satisfaction or stress levels). I identified only limited research that would link the extent of

\footnotetext{
${ }^{1}$ Unless stated differently I use adjective gay to represent both lesbians and gays.

${ }^{2}$ European Union Agency for Fundamental Rights (FRA). (2016). European Union Lesbian, Gay, Bisexual and Transgender Survey, 2012: Special Licence Access. [data collection]. UK Data Service. SN: 7956, http://doi. org/10.5255/UKDA-SN-7956-1.
} 


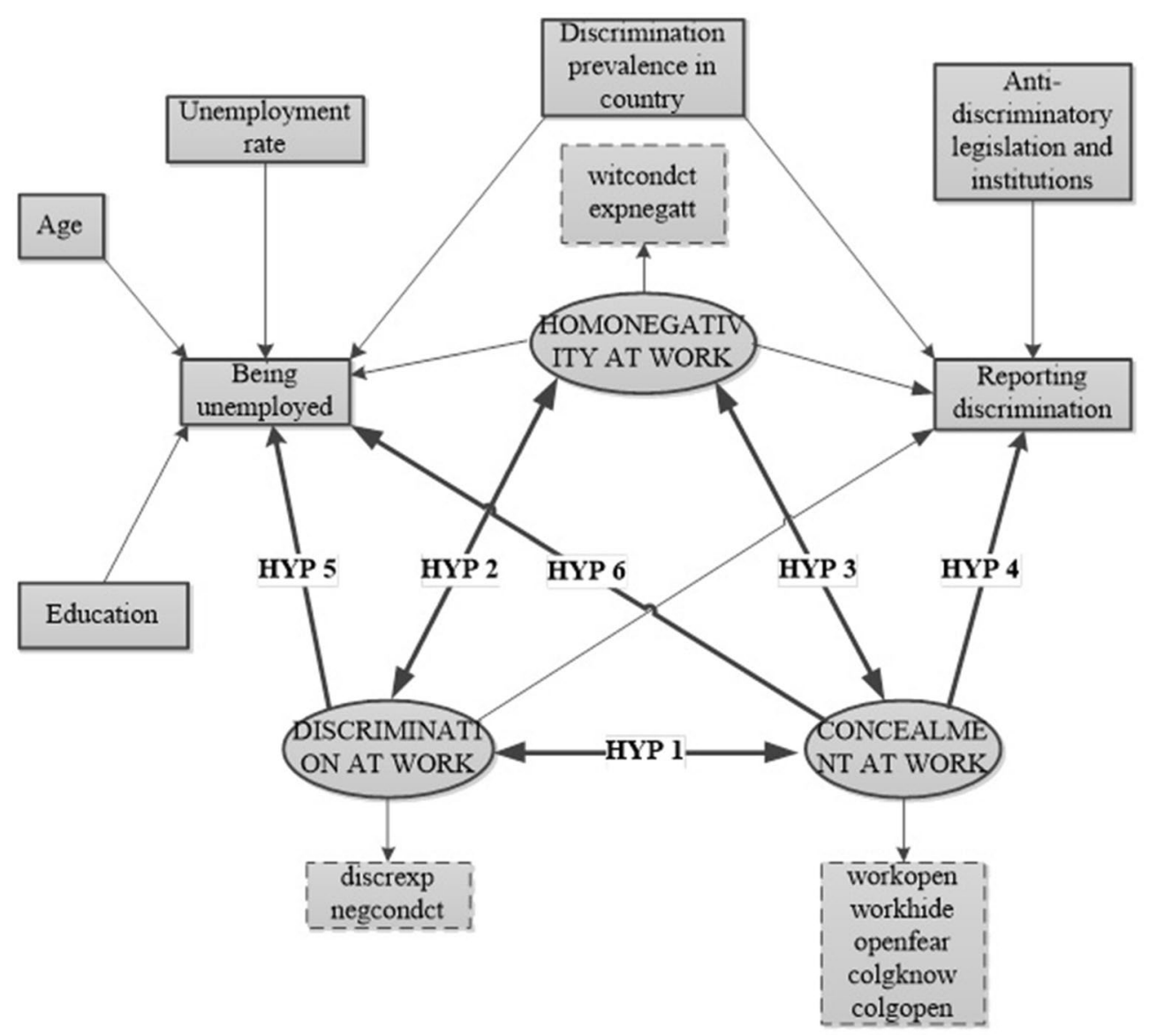

Fig. 1 The model of causalities related to sexual orientation discrimination in the workplace and the path model for the structural equation model

disclosure of sexual orientation in the workplace to perceived discrimination. For example, Ragins and Cornwell (2001) found that gay employees were more likely to conceal their sexual orientation at work (and to have turnover intentions) if they perceived greater workplace discrimination than those who reported less discrimination. According to Ragins et al. (2007), perceptions of past discrimination positively predicted fears about disclosure of sexual orientation. Surprisingly, perceptions of past discrimination were positively related to the extent of disclosure of sexual orientation in current positions. Schneider (1986) observed that prior job loss due to disclosure of sexual identity impacted subsequent decisions and concerns about revealing one's sexuality to co-workers.

\section{Theoretical background}

To test the relationships between (perceived) discrimination, employment status and reporting discrimination, I formulate a model which also encompasses the concepts of disclosure of sexual orientation and homonegativity in the workplace. The model also takes into account contextual factors and a subject's demographic characteristics which are presumed to affect the observed outcomes.

In this section I describe the relevant concepts and how they relate to each other. Based on this I formulate the hypotheses. My model is schematically depicted in Fig. 1. Bold lines mark the hypothesised relationships. Non-bold lines stand for control variables. The singleheaded arrows indicate causality (from the antecedent to the consequent) and double-headed arrows mutual relationship.

Employment status in this article refers to being (un) employed. Sexual orientation discrimination is defined as a less favourable treatment in the labour market because of one's sexual orientation. This definition excludes socalled positive discrimination and is more restrictive than the definition by Arrow (1973), according to whom labour market discrimination exists when two equally qualified individuals are treated differently in the labour market on the basis of a personal characteristic unrelated to productivity. 
The term homonegativity is used as a synonym for sexual prejudice ${ }^{3}$ against lesbians and gays. Even though homonegativity and discrimination in the workplace are conceptually closely related, I treat them as two distinct concepts. Discrimination refers to discriminatory incidents or negative conduct perceived by the subjects that were targeted at themselves. Homonegativity relates to a subjects' perception of attitudes, climate and conduct towards gay people in their workplace in general (i.e. not directly targeted at the subjects themselves).

\subsection{Concealment at work $\leftrightarrow$ discrimination at work}

Even though people can reportedly estimate one's sexual orientation based on body movements (Johnson et al. 2007), facial cues (Freeman et al. 2010; Brewer and Lyons 2017) or voice (Fasoli et al. 2017), sexual orientation is traditionally viewed as a non-observable type of diversity (Milliken and Martins 1996). Direct discrimination on basis of sexual orientation requires knowledge or suspicion that an employee is gay. Gay people may not experience direct discrimination if no one knows or suspects that they are gay, even though they may experience indirect discrimination through the presence of a hostile environment (Ragins and Cornwell 2001).

The model by Chung (2001) postulates that identity management is one of strategies that gay employees can use to cope with potential discrimination. The level of concealment (disclosure) is assumed to affect the extent of discriminatory behaviour.

But there is also an opposite causality. While deciding on how to manage information related to their sexual orientation, gay people assess the benefits and costs of coming out (Rostosky and Riggle 2002). Because disclosure of one's sexual orientation can increase the risk of social rejection, prejudice and discrimination (Chaudoir and Fisher 2010), gay employees are more likely to conceal when they fear discrimination and stigma (see stigma theory by Ragins and Cornwell 2001).

Hypothesis 1 The concealment of sexual orientation in the workplace will be positively related to perceived discrimination.

To correctly estimate the relationship between the concealment of sexual orientation and perceived discrimination in the workplace, homonegativity needs to be taken into account.

\footnotetext{
${ }^{3}$ The term sexual prejudice refers to negative attitudes towards individuals because of their sexual orientation (Herek 2000).
}

\subsection{Homonegativity at work $\leftrightarrow$ discrimination at work}

Homosexuality is still associated with stigma in Western societies. Theory and research have consistently indicated that stigmas evoke negative attributions about the target and that they lead to prejudice (Ragins et al. 2007). Prejudice often predicts discrimination toward persons with stigmatized identities (Pichler et al. 2010) even though other factors moderate this relationship (Herek 2000). For example, prejudiced individuals may be guarded about expressing overt, formal forms of discrimination but they may still exhibit-perhaps unintentionally-bias in more subtle ways.

An opposite causality may also take place. Presence of discrimination may affect the level of negativity against lesbians and gays. Following the justification-suppression model of Crandall and Eshleman (2003), expression of prejudice is restrained by individual's beliefs, values and social norms. Tolerance of anti-gay discriminatory behaviour in the workplace may be seen as legitimization of prejudice against gay people and exacerbate its level.

Hypothesis 2 The homonegativity in the workplace will be positively related to perceived discrimination.

\subsection{Homonegativity at work $\leftrightarrow$ Concealment at work}

The model of managing concealable stigmas at work views anticipated acceptance of the concealable stigma as the primary predictor of revealing or concealing the stigma. The acceptance refers to interpersonal/organisational climate, culture, policies, procedures and representation of LGBT in the organisation. Gay people are expected to conceal (reveal) their sexual orientation more if they perceive the environment as more rejecting (accepting). When a gay person is not certain to what extent they should disclose sexual orientation, they may use information seeking behaviours-so-called signalling (Jones and King 2013).

In an opposite direction, disclosure of sexual orientation in the workplace is expected to influence the attitudes towards gay people. (Previous) exposure to homosexuality or knowledge of a gay person is related to individual's attitudes towards homosexuality-the less people are in a (conscious) contact with gays and lesbians, the more hostile attitudes they have toward them (see for example Herek and Capitanio 1996; Estrada and Weiss 1999; Basow and Johnson 2000; Cotten-Huston and Waite 2000; Levina et al. 2000; Horvath and Ryan 2003).

Hypothesis 3 The concealment of sexual orientation in the workplace will be positively related to the homonegativity in the workplace. 
In the model I link the concepts of concealment, homonegativity and perceived discrimination at work to reporting discriminatory incidents and to the probability of being unemployed.

\subsection{Reporting discrimination}

Reporting covers different actions such as confiding in a trusted person, confronting the perpetrator(s), engaging management, or taking legal action. According to Stangor et al. (2003), discriminatory incidents are reported only if they are suspected and affirmed as such by the victim. This is more likely with certain types of behaviour or perpetrators and it depends on a victim's cognitive, affective and motivational processes. When deciding whether to report/confront discrimination publicly, the victims weigh the costs and benefits of reporting.

Most people who experience discrimination do not file a formal claim (Bell et al. 2013). The reluctance to report discrimination (particularly to authorities or legal institutions) partly stems from the perception that the costs of reporting discrimination are too severe (fear of retaliation or being perceived as a troublemaker) (Major and Kaiser 2008). Gay people face an additional cost if they (partly) conceal their sexual orientation. Publicly reporting discrimination could involve spreading awareness about their sexual orientation. This is particularly undesirable in an environment hostile towards gays and lesbians.

Hypothesis 4 Concealment of sexual orientation by gay people will be negatively related to reporting discrimination.

\subsection{Being unemployed}

Research suggests that gays (and depending on a study also lesbians) have different unemployment probabilities than their straight counterparts. This difference is usually explained by labour demand and labour supply factors. I concentrate on factors related to (the experience of) discrimination. For a more thorough theoretical overview see Fric (2017).

Bell et al. (2013) postulate that stigmatised individuals can be disadvantaged in access to employment or in treatment (compensation, promotion, harassment, etc.). A specific case of differential treatment is discriminatory job loss which is an involuntary separation due to inequitable treatment based on personal factors that are irrelevant to performance.

Discrimination may have feedback effects on the behaviour of the victim. Neoclassical labour supply theory extended with the concept of cognitive dissonance suggests that discriminated workers may cut back labour supply or withdraw from the labour market altogether (Goldsmith et al. 2004). This is supported by the empirical evidence (Habtegiorgis and Paradies 2013). Discrimination may also negatively affect the employee's motivation, self-esteem and self-efficacy which play an important role in access to employment (Kanfer et al. 2001).

Discrimination can also negatively impact an employee's labour market prospects. Victims are less likely to receive good references and stating discrimination as a reason for leaving the previous employer can be detrimental for employment chances. The resulting prolonged unemployment makes it even more difficult to become re-employed as lengthy unemployment is a signal to employers that something is "wrong" with the applicant (Goffman 2009).

Because discrimination may lead to job separation, longer expected unemployment duration and decreased labour supply, I hypothesise that:

Hypothesis 5 Perceived discrimination will be positively related to the probability of being unemployed.

Given that homosexuality is a non-observable stigma and that discrimination is more likely to occur when gay people disclose their sexual orientation, I assume that ceteris paribus:

Hypothesis 6 The concealment of sexual orientation in the workplace will be negatively related to the probability of being unemployed.

Hypotheses 1 to 4 partly replicate previous research and they allow to control for important contextual factors in which relationships tested by hypotheses 5 and 6 take place. Testing hypotheses 5 and 6 represents the main contribution of this paper. Their importance goes beyond the academic research-because unemployment can be detrimental to individual's socioeconomic status, the potential significant relationship between unemployment and perceived workplace discrimination/concealment of sexual orientation could have policy implications.

\subsection{Other predictors}

The relationships in the model may be influenced by contextual factors and subjects' demographic characteristics. To account for such effects, I control for unemployment rate, presence of anti-discriminatory legislation, perception of prevalence of general discrimination against lesbians/gays in a given country (which is a distinct concept from the perception of discrimination in the workplace against oneself), subjects' education, and age. 
It is important to control for sex because of different challenges that gays and lesbians face in the labour market. While there is relatively consistent evidence that gays are disadvantaged compared to heterosexual men, the position of lesbians compared to heterosexual women seems to be more questionable (Drydakis 2014; Fric 2017). The reason may be that public attitudes towards gays are less positive than towards lesbians, especially in heterosexual men (see for example the meta-analysis by Kite and Whitley 1996). Gays are also commonly stereotyped as feminine or effeminate while lesbians are often believed to be overly masculine (Tilcsik 2011). Given these different perceptions, the behaviour of employers, colleagues or customers toward gays and lesbians may not be uniform. To account for these differences I formulate separate Structural Equation Model (SEM) models for gays and lesbians and in logistic regression models I introduce interaction terms with sex.

\section{Data}

I used data from the EU LGBT survey which was conducted by the European Union Agency for Fundamental Rights in 27 European Union Member States and Croatia between April and July 2012. The total sample of the survey is 93,079 respondents, whereof 59,490 identified themselves as gay and 16,170 as lesbian. The EU LGBT survey was not carried out as an online non-random survey because of lacking a sampling frame, target population characteristics and a consensus on the operational definition of LGBT people. The participants were selfselected and had to "opt-in" into the survey. This may have excluded respondents who are less motivated to take part in the survey. The survey was mostly promoted through online media and LGBT organisations which could affect the sample composition: groups with higher access to- and use of internet (young, more-educated, higher-income and male respondents) may be overrepresented (FRA 2013).

One of the main advantages of the EU LGBT survey is that it includes measures of sexual orientation. This often not the case in other large scale surveys or censuses. As a self-administered, online survey guaranteeing full anonymity to its respondents it decreases the risk of respondents concealing information about their sexual orientation because of social desirability bias (Robertson et al. 2017). The survey also provides information on respondents' experiences in the workplace and the extent to which they hide (disclose) their sexual orientation. This information is not matched by surveys that are representative for the whole population and that (in some waves) include measures of sexual orientation.

For the purpose of my research I kept only respondents who are gays or lesbians and who are not transgender.
Table 1 Descriptive statistics of the survey sample used in the analysis, split by sex

\begin{tabular}{|c|c|c|c|c|}
\hline & \multicolumn{2}{|l|}{ Gays } & \multicolumn{2}{|c|}{ Lesbians } \\
\hline & $n$ & $\%$ & $n$ & $\%$ \\
\hline \multicolumn{5}{|l|}{ Age } \\
\hline $18-29$ & 19,004 & 39.5 & 6410 & 52.4 \\
\hline $30-39$ & 14,281 & 29.7 & 3430 & 28.0 \\
\hline $40-49$ & 10,036 & 20.8 & 1680 & 13.7 \\
\hline $50-59$ & 3814 & 7.9 & 585 & 4.8 \\
\hline $60+$ & 1026 & 2.1 & 135 & 1.1 \\
\hline \multicolumn{5}{|l|}{ Education } \\
\hline No formal & 45 & 0.1 & 16 & 0.1 \\
\hline Primary & 580 & 1.2 & 180 & 1.5 \\
\hline Secondary & 11,652 & 24.2 & 2763 & 22.6 \\
\hline Post-secondary & 7117 & 14.8 & 1682 & 13.7 \\
\hline Tertiary & 27,813 & 57.8 & 7286 & 59.5 \\
\hline Other & 954 & 2.0 & 313 & 2.6 \\
\hline \multicolumn{5}{|l|}{ Household income (net) } \\
\hline$<1$ st quartile $\left(Q_{1}\right)$ & 11,628 & $24.1 \%$ & 3626 & 29.6 \\
\hline Between $\mathrm{Q}_{1}$ and $\mathrm{Q}_{2}$ & 12,136 & $25.2 \%$ & 3211 & 26.2 \\
\hline Between $\mathrm{Q}_{2}$ and $\mathrm{Q}_{3}$ & 10,698 & $22.2 \%$ & 2813 & 23.0 \\
\hline Higher than $\mathrm{Q}_{3}$ & 13,699 & $28.4 \%$ & 2590 & 21.2 \\
\hline Total & 48,161 & 100.0 & 12,240 & 100.0 \\
\hline
\end{tabular}

The reason for exclusion of bisexual and transgender respondents is that they may face specific issues that are not covered by this study. Laumann et al. (1994) define homosexuality according to three dimensions-sexual behaviour, desire and self-identification. Because selfidentification is arguably the most important in the workplace context (from all dimensions this one is most probable to be observed by the employer and colleagues), I identified gay people according to this dimension.

In my analysis I only included respondents who had a paid job in the 5 years preceding the survey. This threshold was chosen because some variables used for operationalisation of my theoretical concepts relate to respondents' behaviour and experiences in employment during the 5 years preceding the survey. After checking for the consistency and completeness of respondents' answers, I dropped 15,259 (20.2\%) observations which were incomplete or inconsistent. The final sample used for the analysis consisted of 48,161 gays and 12,240 lesbians. Table 1 provides descriptive statistics of the sample.

Based on the original data I calculated several new variables. The overview of all variables used in the analysis is provided in Table 2. I briefly discuss the most important variables-reporting, unemployed, concealment, homonegativity and perceived discrimination.

The dummy variable reporting captures whether the most recent discrimination incident at work was reported 
Table 2 Overview of variables used in the analysis, sorted alphabetically

\begin{tabular}{|c|c|c|}
\hline Variable & Explanation & Values \\
\hline age & Age of the respondent in years & 1 (18-29), 2 (30-49) or 3 (50 or more) \\
\hline colgknow & $\begin{array}{l}\text { In respondent's opinion, how many work colleagues or } \\
\text { schoolmates know that respondent is gay }\end{array}$ & 1 (none), 2 (a few), 3 (most) or 4 (all) \\
\hline colgopen & $\begin{array}{l}\text { To how many work colleagues or schoolmates is respond- } \\
\text { ent open about being gay }\end{array}$ & 1 (none), 2 (a few), 3 (most) or 4 (all) \\
\hline concealment (only LRM) & Index of concealment of sexual orientation at work & Scale from 0 to 1, higher value stands for more concealment \\
\hline discrexp & $\begin{array}{l}\text { During } 12 \text { months preceding the survey, the respondent } \\
\text { has personally felt discriminated against because of } \\
\text { being gay at work }\end{array}$ & 0 (no) and 1 (yes) \\
\hline discrprev & $\begin{array}{l}\text { Country-level index capturing the arithmetic average of } \\
\text { answers of lesbians (gays) on how prevalent is discrimina- } \\
\text { tion against lesbians (gays) in their country. The respond- } \\
\text { ents are assigned the value corresponding to their sex }\end{array}$ & $\begin{array}{l}\text { Scale from } 0 \text { to 1, higher value stands for more better legal } \\
\text { situation for gays and lesbians }\end{array}$ \\
\hline education & $\begin{array}{l}\text { The highest level of education that the respondent } \\
\text { achieved }\end{array}$ & $\begin{array}{l}1 \text { (primary or lower), } 2 \text { (secondary), } 3 \text { (post-secondary other } \\
\text { than college/university), } 4 \text { (college/university/or higher) }\end{array}$ \\
\hline expnegatt & $\begin{array}{l}\text { During employment in the } 5 \text { years preceding the survey, } \\
\text { the respondent experienced a general negative attitude } \\
\text { at work against people because they are LGBT }\end{array}$ & 1 (never), 2 (rarely), 3 (often) or 4 (always) \\
\hline homonegativity (only LRM) & Index of homonegativity at work & $\begin{array}{l}\text { Scale from } 0 \text { to 1, higher value stands for more homonega- } \\
\text { tivity }\end{array}$ \\
\hline legislation & $\begin{array}{l}\text { Index on legal situation regarding equality and non-dis- } \\
\text { crimination based on sexual orientation. It is calculated } \\
\text { from ILGA Rainbow Index } 2012 \text { (ILGA Europe 2012) and it } \\
\text { captures protection from discrimination by constitution, } \\
\text { in employment, in goods and services, in other spheres } \\
\text { of life, by equality body mandate or by equality action } \\
\text { plan. The index is obtained by dividing the actual country } \\
\text { score by the maximum score the country can achieve }\end{array}$ & $\begin{array}{l}\text { Scale from } 0 \text { to 1, higher value stands for more better legal } \\
\text { situation for gays and lesbians }\end{array}$ \\
\hline negcondct & $\begin{array}{l}\text { During employment in the } 5 \text { years preceding the survey, } \\
\text { the respondent experienced negative comments or } \\
\text { conduct at work because of you being gay }\end{array}$ & 1 (never), 2 (rarely), 3 (often) or 4 (always) \\
\hline openfear & $\begin{array}{l}\text { The respondent avoids being open about being gay in } \\
\text { the workplace for fear of being assaulted, threatened or } \\
\text { harassed by others }\end{array}$ & 0 (no) and 1 (yes) \\
\hline percdiscr (only LRM) & Index of perceived discrimination at work & $\begin{array}{l}\text { Scale from } 0 \text { to } 1 \text {, higher value stands for more perceived } \\
\text { discrimination }\end{array}$ \\
\hline reporting & $\begin{array}{l}\text { The most recent discrimination incident was reported by } \\
\text { the respondent or anyone else }\end{array}$ & 0 (no) and 1 (yes) \\
\hline unemployed & $\begin{array}{l}\text { Variable capturing whether a respondent's current employ- } \\
\text { ment status is unemployed }\end{array}$ & 0 (no) and 1 (yes) \\
\hline unemployment rate & $\begin{array}{l}\text { The annual average unemployment rate per country in } \\
\text { 2012, based on variable une_rt_a from Labour Force } \\
\text { Survey (Eurostat 2017). The separate unemployment rates } \\
\text { per sex are not used because the labour market attach- } \\
\text { ment of lesbians (gays) partly resembles the attachment } \\
\text { of heterosexual men (women) (Fric 2017) }\end{array}$ & $\%$ of unemployed people on active population \\
\hline witcondct & $\begin{array}{l}\text { During employment in the } 5 \text { years preceding the survey, } \\
\text { the respondent heard or seen negative comments or } \\
\text { conduct because a colleague is perceived to be LGBT }\end{array}$ & 1 (never), 2 (rarely), 3 (often) or 4 (always) \\
\hline workhide & $\begin{array}{l}\text { During employment in the } 5 \text { years preceding the survey, } \\
\text { the respondent has hidden or disguised being gay at } \\
\text { work }\end{array}$ & 1 (never), 2 (rarely), 3 (often) or 4 (always) \\
\hline workopen & $\begin{array}{l}\text { During employment in the } 5 \text { years preceding the survey, } \\
\text { the respondent has been open about you being gay at } \\
\text { work }\end{array}$ & 1 (never), 2 (rarely), 3 (often) or 4 (always) \\
\hline
\end{tabular}


by the respondent or someone else. It obtains non-missing values only for respondents who felt personally discriminated in the 12 months preceding the survey and for whom the most recent discrimination incident happened at work (in total 6843 observations). For all other observations reporting was coded as missing because no information was available on whether a potential discrimination incident at work was reported or not. ${ }^{4}$ More detailed analysis into who reported the discriminatory incidents, to whom and how, was not possible because the survey does not provide such information.

The dummy variable unemployed captures respondents' employment status. Respondents are seen as unemployed if they had a job anytime during the 5 years preceding the survey and reported their current status as 'unemployed'. My definition of unemployment is broader than the official definition by the International Labour Organization (1982). I treat all respondents as unemployed if they reported so, disregarding whether they are available or looking for a job. This is done so as to not exclude those who became discouraged after experiencing workplace discrimination and dropped out of the labour force (Leppel 2009). I replicated the analysis and excluded unemployed respondents who were not looking for a job in the past 12 months and I came to the same conclusions. Observations for those whose current employment status was student, retired person, person in unpaid work or other and observations with inconsistencies were assigned a missing value.

The variables concealment, homonegativity and perceived discrimination are individual level indices capturing concealment of sexual orientation, homonegativity and perceived discrimination in the workplace that were reported by the respondents. They are used in the logistic regression models but not in the structural equation models (see "Method" section). Regarding homonegativity, the EU LGBT Survey didn't include any questions that directly captured the workplace attitudes toward gay people. For this reason, I used a proxy measure based on the respondent's report of (1) witnessing negative comments or conduct against colleague(s) perceived to be LGBT and (2) experiencing generally negative attitude at work against LGBT people. I assume that this proxy measure is strongly positively related with the concept of homonegativity.

Figures 2 and 3 summarise the relative incidence of unemployment in gays and lesbians as a function of

\footnotetext{
${ }^{4}$ In the EU LGBT survey, the respondents are asked whether they felt discriminated in the past 12 months (question $c 4$ ) and where the most recent incident of discrimination took place (question $c 5$ ). The information on whether discriminatory incident at work was reported or not (variable $c 6$ ) is available only if it was respondent's most recent incident.
}

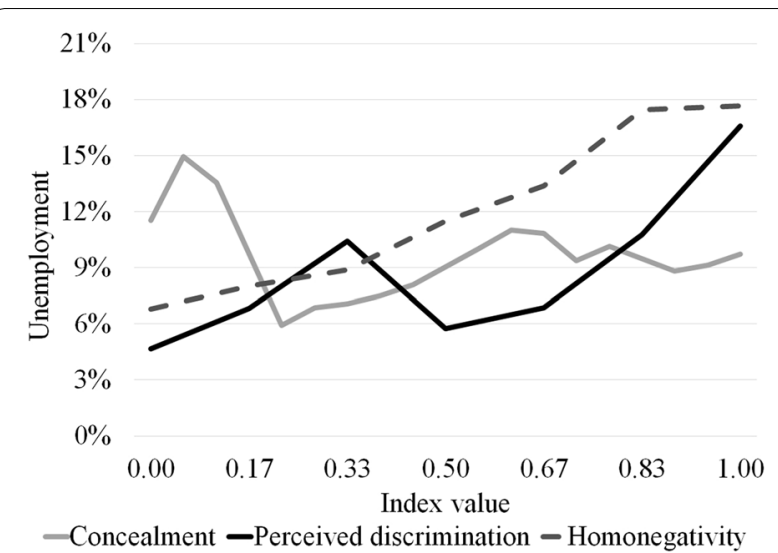

Fig. 2 Unemployment rate of gays (in \%) depending on the value of concealment, perceived discrimination and homonegativity indeces

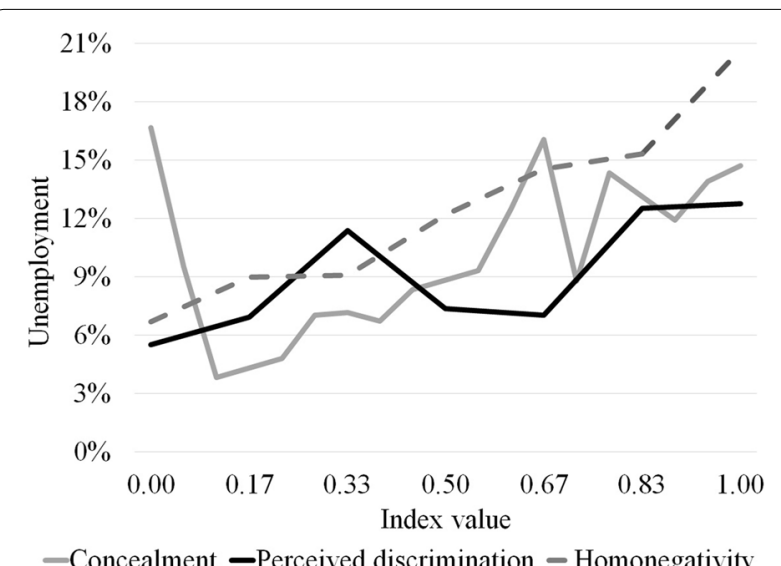

Fig. 3 Unemployment rate of lesbians (in \%) depending on the value of concealment, perceived discrimination and homonegativity indeces

indices of concealment, homonegativity and perceived discrimination. ${ }^{5}$ There appears to be an U-shaped relationship between concealment and respondents' unemployment rate-respondents who are very overt or very closed about their sexuality at work seem to have a higher unemployment rates than those who engage in a more elaborate identity management. Both perceived discrimination and (especially) homonegativity seem to have a positive linear relationship with the unemployment rate.

In the SEM, the core concepts of the model-homonegativity, concealment and discrimination at work-are

\footnotetext{
${ }^{5}$ An interested reader can find detailed statistics from the survey in the survey data explorer at https://fra.europa.eu/en/publications-and-resources/ data-and-maps/survey-fundamental-rights-lesbian-gay-bisexual-and. Note that some statistics may differ from those reported here because I dropped observations with inconsistencies.
} 
latent variables operationalised using multiple variables. Figure 1 shows in dashed rectangles which variables were used to operationalise each concept. More details on the calculation of the concepts are provided in "Method" section.

\section{Method}

The model described in the section Theoretical background assumes several co-dependencies between the theorised concepts (see the path model in Fig. 1). Given the complexity of the model, the SEM technique was used for the estimation. The concepts of homonegativity, concealment and discrimination at work are unobservable and are treated as latent constructs. In the path model they are shown in ovals and the double-headed arrows between them symbolise that they are mutually correlated. They are grounded by manifest variables (shown in dashed rectangles) which are observable.

SEM assumes continuous and multivariate normally distributed data in the population (Finney and DiStefano 2006). By using the Shapiro-Wilk test I found that the data violates the normality assumption. Moreover, variables discrexp, openfear, reporting and unemployed are dichotomous variables with Bernoulli distribution and variables age, workopen, workhide, negcondct, witcondct, expnegatt, education, colgknow and colgopen are categorical variables. This could result in incorrect standard errors of model parameter estimates. For this reason I apply the Generalised Structural Equation Model, which doesn't assume multivariate normal distribution and can handle non-continuous data. I specify a measurement model, which relates responses to latent variables (Skrondal and Rabe-Hesketh 2005).

Following Skrondal and Rabe-Hesketh (2005), I formulate the measurement model as

$$
x_{j}^{*}=v+\mathrm{B} z+\Lambda \xi+\delta_{j},
$$

for latent response variables unemployed and reporting. For all other latent response variables, the measurement model is formulated as

$$
x_{j}^{*}=v+\Lambda \xi+\delta_{j},
$$

where $x_{j}^{*}$ are latent continuous responses, $v$ a vector of intercepts, $\Lambda$ a factor loading matrix, $\xi$ a vector of latent variables, $\delta$ a vector of unique factors for $j$ index units. $\mathrm{B}$ is a regression parameter matrix for the regression of $x_{j}^{*}$ on a vector of observed explanatory variables $z$ (the demographic and country-level control variables) ${ }^{6}$

\footnotetext{
${ }^{6}$ The variable reporting has only a limited amount of observations with known values, which considerably limits the sample size for model which has reporting as dependent variable. In this model I therefore don't include age and education as control variables.
}

The observed categorical response $x_{i j}$ is related to latent continuous response $x_{i j}^{*}$ via a threshold model. For ordinal observed responses I assume that

$$
x_{i j}=\left\{\begin{array}{ccc}
0 & \text { if } & -\infty<x_{i j}^{*} \leq k_{1 i} \\
1 & \text { if } & k_{1 i}<x_{i j}^{*} \leq k_{2 i} \\
& & \vdots \\
S & \text { if } & k_{S i}<x_{i j}^{*} \leq \infty
\end{array}\right.
$$

Dichotomous observed responses are a special case where $S=1$.

I use generalised latent variables model, with a measurement model in forms

$$
g\left(\mu_{j}\right)=v+\Lambda \xi+\mathrm{B} z
$$

for the variables unemployed and reporting, while for all other variables it has form

$$
g\left(\mu_{j}\right)=v+\Lambda \xi
$$

where $g(\cdot)$ is a vector of link functions and $\mu_{j}$ a vector of conditional means of the responses given quantities as defined in Eqs. (1a) and (1b). Because I use dichotomous and categorical variables, I select logit as the link function:

$$
\operatorname{logit}\left(\mu_{j}\right)=\ln \left(\frac{\operatorname{Pr}\left(\mu_{j}\right)}{1-\operatorname{Pr}\left(\mu_{j}\right)}\right)=v+\Lambda \xi+\mathrm{B} z
$$

for variables unemployed and reporting and for all other variables

$$
\operatorname{logit}\left(\mu_{j}\right)=\ln \left(\frac{\operatorname{Pr}\left(\mu_{j}\right)}{1-\operatorname{Pr}\left(\mu_{j}\right)}\right)=v+\Lambda \xi .
$$

To fit the model, I used the gsem procedure in Stata software. ${ }^{7}$ Because the maximum likelihood estimation method formally assumes conditional normality, the option robust has been selected during the calculation. The reported results are therefore robust to heteroscedasticity of the errors (StataCorp LP 2013).

The gsem procedure deletes the missing values equation-wise. This means that a given observation will not be used in equations containing a variable where this observation has a missing value (and in products of such equations) (StataCorp LP 2013). To fit the specified model I used the alternative-starting-values procedure as described in StataCorp LP (2013). This entailed that I

\footnotetext{
${ }^{7}$ StataCorp. (2013). Stata Statistical Software: Release 13.1. College Station, TX: StataCorp LP.
} 
firstly fitted a simplified model and used its solution as starting values to fit a more complex model. I repeated this procedure until I was able to fit the original model. ${ }^{8}$ Because of differences between gays and lesbians (as described in "Theoretical background" section), I fitted two separate models-one for gays and another for lesbians. The current version of Stata doesn't support calculation of goodness of fit statistics for the gsem model. For this reason I do not report goodness of fit statistics for my SEM throughout the paper.

To control the validity of the results from the SEM with regards to hypotheses 4, 5 and 6, I fitted six logistic regression models (LRM) specified as follows:

$$
\operatorname{logit}(y)=\ln \left(\frac{\operatorname{Pr}(y)}{1-\operatorname{Pr}(y)}\right)=\alpha+\mathrm{B} x_{k}
$$

where $y$ refers to the dependent variable, $\alpha$ to the intercept, $x_{k}$ to the vector of $k$ explanatory variables and B to regression parameter matrix. I specified three models for both independent variables unemployed and reporting. The models include a base model, a model with country dummy variables and a model with interactions with sex.

Potential differences in the results between SEM and LRM could be caused by the following factors:

- SEM estimates the whole model as shown in Fig. 1 while LRM estimates separate models for probability of unemployment/reporting discrimination;

- Workplace homonegativity, perceived discrimination and concealment of sexual orientation are calculated differently in both methods-as latent variables in SEM and as indices in LRM;

- LRM doesn't assume a mutual relationship between workplace homonegativity, perceived discrimination and concealment of sexual orientation while SEM does;

- Incorrect specification of the model(s).

\section{Outcomes}

The results of the SEM and LRM were similar unless stated otherwise. The outcomes of the SEM are illustrated in Fig. 4. The full output of SEM is reported in table A1 in the annex and the outcomes of the LRM in table A2.

Consistently with Hypothesis 1, there was a weak positive (and significant) correlation between the concealment of sexual orientation and perceived discrimination in the workplace for both lesbians and gays. In other

\footnotetext{
8 The full syntax is available upon request.
}

words subjects who are less open about their homosexuality more often report that they feel discriminated. This relationship is also mediated by homonegativity: perceived discrimination is strongly positively correlated with homonegativity (as predicted by hypothesis 2) and homonegativity has a moderately strong positive correlation to concealment (confirming hypothesis 3 ). The latter is consistent with the model of managing concealable stigmas at work by Jones and King (2013) according to which lesbians and gays conceal their sexuality more in hostile environments.

Consistently with Hypothesis 4, a discriminatory incident is less likely to be reported by the subjects who are less open about their sexuality. The LRM shows weakly statistically significant effect of sex where the level of concealment has a more profound negative effect on lesbians' readiness to report discrimination than in case of gays. Reporting is also positively associated to perceived discrimination and negatively to homonegativity in the workplace (although the latter is not significant for lesbians).

The findings regarding contextual variables are less consistent across sex. Presence of anti-discriminatory legislation and institutions is negatively related to gays' probability of reporting a discriminatory incident, while the positive effect is found in lesbians (though lacking statistical significance in the SEM). LRM confirms that the difference between lesbians and gays is statistically significant. The finding for gays is remarkable-discrimination incidents are less likely to be reported in countries with more extensive anti-discrimination legislation and institutions. This could indicate that anti-discrimination legislation and institutions on its own do not increase readiness to report discrimination. An alternative explanation could be that the nature of discrimination differs between countries and that it is possibly less serious (and hence less likely to be reported) in countries with more extensive legal protection.

The effect of public attitudes on discrimination reporting is consistent between SEM and LRM. Lesbians are more likely to report discrimination in countries with more negative public attitudes but for gays this relationship is negative and weak. The difference between gays and lesbians is statistically significant (see the model with interactions in LRM).

In agreement with Hypothesis 5, lesbians and gays who perceived being discriminated at work were statistically significantly more likely to be unemployed (in both SEM and LRM). The interaction term with sex was not significant meaning that discrimination perception doesn't relate to unemployment probability differently in lesbians compared to gays. I will discuss these outcomes in a more detail in the following section. 


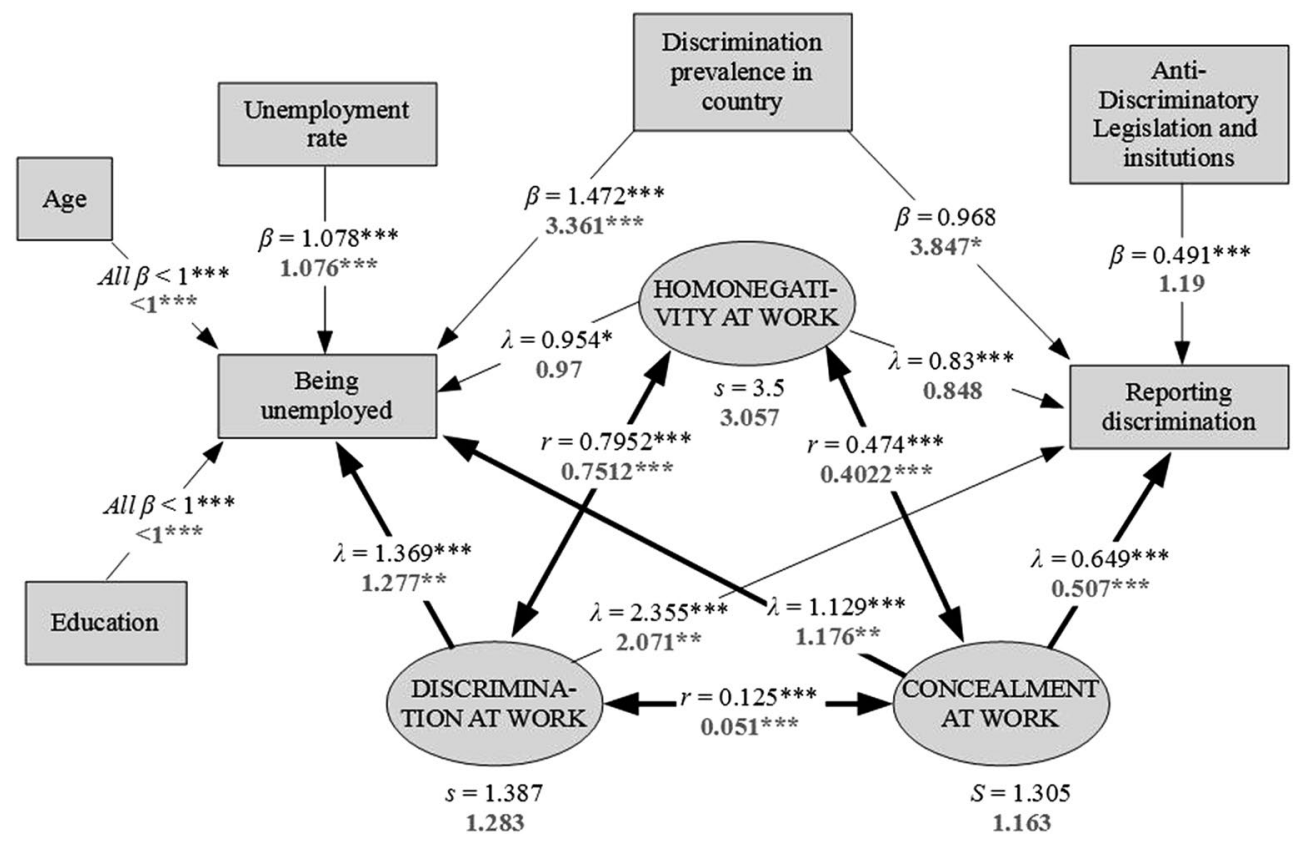

Fig. 4 Summary of results of SEM analysis. Estimates for gays are shown in black font and estimates for lesbians are shown in grey bold font. Start sign * means that the coefficient is statistically significant at $5 \%,{ }^{* *}$ at $1 \%$ and ${ }^{* * *}$ at $0.1 \%$. r refers to correlation coefficient, $\beta$ to odds ratios of logistic regression for observed independent variables (shown in rectangles) and $\lambda$ to odds ratios of logistic regression for latent exogenous variables (shown in ovals) with mean 0 and standard deviation $s$. The reference category for variable education is 'Primary education or lower' and for variable age it is'18-29 years old'

In contradiction with hypothesis 6, in SEM concealment of sexual orientation at work was, ceteris paribus, positively and significantly related to unemployment for both lesbians and gays. The LRM confirmed this finding only for lesbians. For gays the unemployment probability and concealment were not statistically significantly related.

Another contradiction between SEM and LRM was found in the relationship between homonegativity and unemployment. In SEM, both variables were negatively related for gays and no statistically significant relationship was found for lesbians. In contrast, homonegativity had a positive association with unemployment in LRM, which became statistically insignificant once I included interactions with sex.

I observed a negative (U-shaped $)^{9}$ relationship between an individual's education attainment (age) and unemployment probability. Country level unemployment rate and discrimination prevalence in country were both positively and statistically significantly related to a subject's probability of being unemployed.

\footnotetext{
${ }^{9} \mathrm{U}$-shaped relationship in SEM for gays and negative relationship in LRM and SEM for lesbians.
}

\section{Discussion}

I have formulated a model of causalities between perceived discrimination, homonegativity and sexual orientation disclosure in the workplace and the reporting of discrimination and an individual's employment status. I have empirically tested the relationships between these concepts using survey data. The main contribution of my approach is that it allowed to simultaneously estimate relationships between several concepts of interest. Because I used cross-sectional data with no time dimension, I could not establish the causal direction in observed relationships (De Vaus 2001). Despite this shortcoming, my analysis provided a number of insights.

\subsection{Being unemployed}

My results indicate that perceived discrimination directed against gay people in the workplace relates to their employment status. As discussed earlier, this could be due to discriminatory job loss or cognitive dissonance. Perceived discrimination can also have an indirect effect on employment status-unfavourable treatment (such as a lower promotion rate or less supportive mentors) can limit career development, especially if accumulated over time. This leads to a comparative disadvantage for discriminated individuals when applying for a 
job even in absence of direct discrimination in access to employment.

The relationship between perceived discrimination and being unemployed is positive and significant for both gays and lesbians. For gays, this is in line with previous research which showed that homosexuality forms a barrier in their access to employment (Fric 2017). However, the literature is inconclusive for lesbians, providing some evidence that-despite being discriminated in accessing employment-lesbians are more probable to be employed compared to heterosexual women (Fric 2017). My findings suggest that workplace discrimination has qualitatively the same impact on lesbians as it has on gays when it comes to the link with unemployment. Hence favourable labour market outcomes of lesbians as to straight women seem to be driven by labour supply factors rather than by (the lack of) discrimination.

What role do concealment of sexual orientation and homonegativity play in this story? The outcomes suggest that (ceteris paribus) the more subjects conceal their sexual orientation at work, the likelier they are to be unemployed. In LRM the convex shape of relationship between concealment and unemployment (shown in Figs. 2 and 3) disappeared once I controlled for individual and contextual variables. These findings are unexpected in light of the theoretical predictions. The review by Fric (2017) indicates that job applicants whose homosexuality is disclosed are disadvantaged (compared to their heterosexual counterparts), especially if the employers are male. Because silence constitutes an implicit claim to be heterosexual (Button 2001), gay people who disclose their sexual orientation should experience a prolonged job search and a higher unemployment rate than those who conceal it. The observed sign of relationship could be caused by other factors for which I didn't control in my analysis. For example, gays and lesbians who are less open about their sexuality may concentrate in sectors (or occupations) with higher general unemployment rate. Or certain personality trait (for example self-esteem) may relate both to higher concealment of sexual orientation and to higher unemployment probability.

The analysis gave an inconsistent answer to how workplace homonegativity relates to unemployment probability. This could indicate that homonegativity affects unemployment mostly indirectly via incidence of discriminatory incidents and via concealment of sexual orientation.

\subsection{Reporting discrimination}

The analysis shows that reporting discriminatory incidents positively relates to perception of discrimination. While this is not a ground-breaking finding, it is worthwhile to look at what roles the concealment of sexual orientation and homonegativity play: subjects who conceal their sexual orientation at work are somehow more likely to perceive being discriminated and less likely to report discrimination. This is coherent with the theoretical prediction that gay people will face additional cost of reporting discrimination if they (partly) conceal their sexual orientation.

Another finding which is consistent with the predictions is that discriminatory incidents will be more likely unreported in workplaces with higher homonegativity. In SEM this relationship was statistically significant only for gays while in LRM for both sexes (the interaction term with sex was not statistically significant). The negative relationship suggests that reporting discriminatory incident has higher perceived costs in environments where homophobic attitudes and conduct are more prevalent. In these contexts, the victims (or witnesses) probably fear the repercussions of reporting discriminatory behaviour more.

\subsection{Practical implications}

The findings indicate the existence of a vicious circle in the workplace, especially for closeted lesbians and gays who work in more hostile workplaces. Even if they fully conceal their sexual orientation, they seem to experience (indirect) discrimination due to a hostile work environment or because their colleagues and/or employer suspects that they are gay. Concealing sexual orientation makes them more vulnerable to discrimination by limiting their possibilities of confronting discriminatory incidents-by reporting such incidents they risk that their sexual orientation would be publicly revealed. The data suggest that discriminatory incidents are less likely to be reported in hostile workplaces. Ironically, these are the workplaces where discrimination and harassment is most likely to occur.

This can explain a relatively low incidence of official discriminatory complaints on the grounds of sexual orientation, especially in countries with relatively more hostile public attitudes toward homosexuality as found by Eurofound (2016). According to EU LGBT survey, less than $13 \%$ of most recent discriminatory incidents in the workplace were (officially) reported. The lack of official complaints is often interpreted as evidence that discrimination against gay people in the European labour market is not frequent. In the light of my findings, the lack of complaints is rather a sign that gay people do not dare to report discriminatory incidents because of pervasive homophobia and fears of their sexuality being publicly revealed. It is noteworthy, that my data only captures discrimination encountered by the respondents. The level of potential discrimination (i.e. discrimination that would 
take place if the respondents' sexual orientation was always fully known) is probably considerably higher.

Finally, the direct and indirect labour market discrimination based on sexual orientation is forbidden in the European Union by the Employment Equality Directive (2000/78/EC). The legislation seems to only partly solve the problem of sexual orientation discrimination. Its effectiveness may be weakened by a low readiness to report discriminatory incidents. Under these circumstances, the policy response could target public attitudes towards homosexuality as a means of influencing workplace homonegativity (which is an important predictor of workplace discrimination). At the same time, the policy should aim to create a safe workplace where lesbians and gays would be comfortable to disclose their sexual orientation and report potential discriminatory incidents.

\subsection{Directions for future research}

Several questions still remain to be answered. Firstly, more research is needed into the relationship between the disclosure of sexual orientation and employment status. What are the channels between (perceived) discrimination and unemployment? Do gay people voluntary choose to leave discriminatory workplaces (or even labour market altogether) or does the job separation follow discriminatory lay off initiated by employers? Or is higher unemployment probability a consequence of comparative disadvantage that gay employees accumulate over time from small discriminatory incidents? Answers to these questions could help to formulate an adequate policy response aiming at decreasing discriminatory job separations of lesbian and gay employees.

More research is also needed into the causalities regarding reporting discriminatory incidents based on sexual orientation. Would my findings vary if different forms of reporting discrimination were concerned (such as engaging the HR department, a trade union or taking a legal action)? And how do different forms of reporting affect a victim's workplace experiences and outcomes? Answers to these questions could help to design effective procedures for reporting and addressing sexual orientation discrimination.

\section{Limitations}

This study has a number of limitations. First of all, the measure of workplace discrimination is based on a subject's perception and as such it is conceptually different from real discrimination. In real life it is often difficult to objectively determine whether discrimination took place or not and subject's perceptions may not necessarily reflect the reality (Chung 2001). So far, the research has made little use of self-reported data on discrimination due to concerns about their validity and bias relating to inflated discrimination reports. Over-reporting of discrimination on a large scale could bias the research results and in my analysis it could lead to establishing a false relationship between perceived discrimination and other constructs (unemployment, etc.). However, the evidence does not support such concerns and in contrast minorities seem to be more likely to underreport their experiences with discrimination (Habtegiorgis and Paradies 2013). Despite these conceptual limitations, perceived discrimination is worth looking at-if an action is perceived as discriminatory, it may adversely impact employees' morale, work attitudes, and job behaviours (Ragins and Cornwell 2001).

Secondly, the measure of reporting discrimination is based on subjects' retrospective reports of how they handled the most recent discriminatory incident. This measure may be biased upwards because subjects tend to recall instances when they reported discrimination rather than instances when they failed to do so. This could result in overestimation of the extent to which discrimination is reported. Besides that, it is difficult to assess the type and severity of discriminatory events that subjects considered (Major and Kaiser 2008). The data also don't distinguish whether the incidents were reported by the subjects themselves or someone else.

The third limitation is connected to using an online survey data. Because of social stigma and privacy concerns, gay people are to a large extent a hidden population. This results in a lack of sampling frame. Online surveys partly address this issue as they are widely accessible and provide subjects with privacy and anonymity. For this reason, online surveys are frequently used to approach gays and lesbians. Their drawback is a limited external validity (Göçmen and Yilmaz 2016). As discussed in "Data" section, some groups of gay and lesbian population may be underrepresented in my sample. I used statistical controls to account for (what I identified as) relevant individual characteristics. However, it remains unclear to what extent I succeeded to control for the most relevant characteristics and whether the sample per se included sufficient information on behaviour and experiences of the least visible strata of the target population. The findings of my study may not be generalizable to the whole population of gay people in the European Union. They are likely to be especially valid for groups that are best represented in the EU LGBT survey, i.e. respondents who are young, more educated, male and possibly those who are more accepting of their sexual orientation and open about it.

Finally, in my analysis I didn't control for variables such as region, occupation, existence of company level policies, etc. This was partly due to data unavailability and partly due to complexity of the proposed model. Inclusion of these variables into the model could provide an additional insight into the examined associations. For example, 
existence of anti-discriminatory company policies could mediate the relationship between workplace homonegativity and reporting of discriminatory incidents. The future research could address this shortcoming.

\section{Conclusion}

I empirically tested how workplace homonegativity, concealment of sexual orientation and discrimination relate to an individual's employment status and the reporting of discriminatory incidents. The results supported the majority of my hypotheses.

The outcomes support the assumption that hostility against gays and lesbians projects into discriminatory behaviour which in turn can justify such prejudice. The results also suggest that stigma theory's prediction that hostility and discrimination against lesbians and gays negatively impacts their readiness to publicly disclose their sexual orientation. An opposite causality is also possible-the lack of (conscious) contact with gay people can increase prejudice and discriminatory behaviour against them. Concealment of sexual orientation seems to form an important barrier in reporting sexual orientation discrimination. The findings also indirectly support the prediction of discriminatory job loss model by Bell et al. (2013) that discrimination may result in job separation. Alternatively, experiencing discrimination could negatively affect one's labour supply via cognitive dissonance.

Contrary to my expectations, I observed a positive relationship between the concealment of sexual orientation in the workplace and an individual's unemployment probability even after controlling for individual and country-specific characteristics.

\section{Acknowledgements}

This article was written under the lead of Prof. Dr. Ferry Koster (Erasmus University Rotterdam) and of Prof. Dr. Romke van der Veen (Erasmus University Rotterdam) and I would like to thank for their advice and support.

\section{Authors' contributions}

The author analysed the data and was the sole contributor to the writing of the manuscript. The author read and approved the final manuscript.

\section{Funding}

Not applicable.

\section{Availability of data and materials}

The datasets analysed during the current study are available in the The UK Data Service repository subject to special licence access". European Union Agency for Fundamental Rights (FRA). (2016). European Union Lesbian, Gay, Bisexual and Transgender Survey, 2012: Special Licence Access. [data collection]. UK Data Service. SN: 7956, http://doi.org/10.5255/UKDA-SN-7956-1

\section{Competing interests}

The author declares that there is no competing interests.

\section{Annex}

See Tables 3 and 4. 
Table 3 Full results of the structural equation model for gays and lesbians

\begin{tabular}{|c|c|c|c|c|c|c|c|}
\hline \multirow[t]{2}{*}{ Dependent variable } & \multirow[t]{2}{*}{ Independent variable(s) } & \multicolumn{3}{|l|}{ Gays } & \multicolumn{3}{|c|}{ Lesbians } \\
\hline & & Coeff. & Robust st. errors & $P>|z|$ & Coeff. & Robust st. errors & $P>|z|$ \\
\hline witcondct & HOMONEG & 1 & (constrained) & & 1 & (constrained) & \\
\hline expnegatt & HOMONEG & 1.010 & 0.025 & 0.000 & 1.093 & 0.054 & 0.000 \\
\hline negcondct & DISCRIM & 2.411 & 0.077 & 0.000 & 2.834 & 0.212 & 0.000 \\
\hline \multirow[t]{2}{*}{ discrexp } & DISCRIM & 1 & (constrained) & & 1 & (constrained) & \\
\hline & constant & -1.442 & 0.019 & 0.000 & -1.297 & 0.035 & 0.000 \\
\hline \multirow[t]{6}{*}{ reporting } & legislation & -0.712 & 0.206 & 0.001 & 0.174 & 0.386 & 0.653 \\
\hline & discrprev & -0.033 & 0.237 & 0.890 & 1.347 & 0.589 & 0.022 \\
\hline & HOMONEG & -0.187 & 0.052 & 0.000 & -0.165 & 0.101 & 0.102 \\
\hline & DISCRIM & 0.857 & 0.151 & 0.000 & 0.728 & 0.276 & 0.008 \\
\hline & CONCEAL & -0.433 & 0.061 & 0.000 & -0.680 & 0.132 & 0.000 \\
\hline & constant & -2.291 & 0.256 & 0.000 & -3.567 & 0.512 & 0.000 \\
\hline \multirow[t]{13}{*}{ Unemployment } & unemp. rate & 0.075 & 0.003 & 0.000 & 0.074 & 0.006 & 0.000 \\
\hline & discrprev & 0.387 & 0.079 & 0.000 & 1.212 & 0.248 & 0.000 \\
\hline & education & & & & & & \\
\hline & Second. ed. & -0.897 & 0.124 & 0.000 & -1.295 & 0.236 & 0.000 \\
\hline & Post-sec. ed. & -1.090 & 0.125 & 0.000 & -1.390 & 0.238 & 0.000 \\
\hline & Coll./univ./higher & -1.519 & 0.121 & 0.000 & -1.978 & 0.230 & 0.000 \\
\hline & age & & & & & & \\
\hline & 30-49 years & -0.540 & 0.039 & 0.000 & -0.548 & 0.079 & 0.000 \\
\hline & $50+$ years & -0.440 & 0.070 & 0.000 & -0.686 & 0.193 & 0.000 \\
\hline & HOMONEG & -0.047 & 0.022 & 0.029 & -0.030 & 0.040 & 0.446 \\
\hline & DISCRIM & 0.314 & 0.050 & 0.000 & 0.245 & 0.090 & 0.007 \\
\hline & CONCEAL & 0.122 & 0.027 & 0.000 & 0.162 & 0.052 & 0.002 \\
\hline & constant & -1.735 & 0.133 & 0.000 & -1.606 & 0.248 & 0.000 \\
\hline \multirow[t]{2}{*}{ openfear } & CONCEAL & 1 & (constrained) & & 1 & (constrained) & \\
\hline & constant & -1.583 & 0.016 & 0.000 & -1.646 & 0.031 & 0.000 \\
\hline colgknow & CONCEAL & -4.159 & 0.084 & 0.000 & -4.558 & 0.199 & 0.000 \\
\hline colgopen & CONCEAL & -4.242 & 0.086 & 0.000 & -4.726 & 0.211 & 0.000 \\
\hline workopen & CONCEAL & -2.776 & 0.045 & 0.000 & -2.390 & 0.080 & 0.000 \\
\hline workhide & CONCEAL & 2.248 & 0.035 & 0.000 & 2.085 & 0.067 & 0.000 \\
\hline \multirow[t]{3}{*}{ witcondct } & /cut1 & -1.368 & 0.027 & 0.000 & -1.703 & 0.054 & 0.000 \\
\hline & /cut2 & 2.684 & 0.039 & 0.000 & 1.985 & 0.059 & 0.000 \\
\hline & /cut3 & 7.022 & 0.090 & 0.000 & 6.263 & 0.146 & 0.000 \\
\hline \multirow[t]{3}{*}{ expnegatt } & /cut1 & -1.296 & 0.027 & 0.000 & -1.989 & 0.065 & 0.000 \\
\hline & /cut2 & 2.731 & 0.040 & 0.000 & 2.130 & 0.069 & 0.000 \\
\hline & /cut3 & 6.885 & 0.090 & 0.000 & 6.711 & 0.178 & 0.000 \\
\hline \multirow[t]{3}{*}{ negcondct } & /cut1 & 0.659 & 0.026 & 0.000 & 0.640 & 0.058 & 0.000 \\
\hline & /cut2 & 5.200 & 0.092 & 0.000 & 5.643 & 0.250 & 0.000 \\
\hline & /cut3 & 8.942 & 0.160 & 0.000 & 9.959 & 0.444 & 0.000 \\
\hline \multirow[t]{3}{*}{ colgknow } & /cut1 & -5.544 & 0.075 & 0.000 & -6.556 & 0.181 & 0.000 \\
\hline & /cut2 & -0.191 & 0.032 & 0.000 & -0.548 & 0.063 & 0.000 \\
\hline & /cut3 & 3.923 & 0.059 & 0.000 & 4.140 & 0.126 & 0.000 \\
\hline \multirow[t]{3}{*}{ colgopen } & /cut1 & -4.556 & 0.069 & 0.000 & -5.972 & 0.183 & 0.000 \\
\hline & /cut2 & 0.412 & 0.033 & 0.000 & -0.108 & 0.065 & 0.094 \\
\hline & /cut3 & 3.769 & 0.058 & 0.000 & 3.719 & 0.123 & 0.000 \\
\hline \multirow[t]{3}{*}{ workopen } & /cut1 & -2.170 & 0.031 & 0.000 & -2.257 & 0.053 & 0.000 \\
\hline & /cut2 & 0.169 & 0.022 & 0.000 & -0.024 & 0.036 & 0.499 \\
\hline & /cut3 & 2.413 & 0.031 & 0.000 & 2.303 & 0.050 & 0.000 \\
\hline
\end{tabular}


Table 3 (continued)

\begin{tabular}{|c|c|c|c|c|c|c|c|c|c|}
\hline \multirow[t]{2}{*}{ Dependent variable } & \multicolumn{2}{|c|}{ Independent variable(s) } & \multicolumn{4}{|l|}{ Gays } & \multicolumn{3}{|c|}{ Lesbians } \\
\hline & & & \multirow{2}{*}{$\begin{array}{l}\text { Coeff. } \\
-1.626\end{array}$} & \multicolumn{2}{|c|}{ Robust st. errors } & $P>|z|$ & Coeff. & Robust st. errors & $P>|z|$ \\
\hline \multirow[t]{3}{*}{ workhide } & /cut1 & & & 0.024 & & 0.000 & -1.891 & 0.044 & 0.000 \\
\hline & /cut2 & & 0.503 & 0.019 & & 0.000 & 0.366 & 0.033 & 0.000 \\
\hline & /cut3 & & 2.335 & 0.026 & & 0.000 & 2.475 & 0.049 & 0.000 \\
\hline \multicolumn{10}{|l|}{ Latent variables } \\
\hline \multicolumn{2}{|l|}{ Description } & Coeff. & \multicolumn{2}{|c|}{ Robust st. errors } & $P>|z|$ & \multicolumn{2}{|c|}{ Coeff. } & Robust st. errors & $P>|z|$ \\
\hline \multicolumn{2}{|l|}{ Variance of HOMONEG } & 12.253 & \multicolumn{3}{|l|}{0.373} & \multicolumn{2}{|c|}{9.343} & 0.538 & \\
\hline \multicolumn{2}{|l|}{ Variance of DISCRIM } & 1.922 & \multicolumn{3}{|l|}{0.071} & \multicolumn{2}{|c|}{1.646} & 0.123 & \\
\hline \multicolumn{2}{|l|}{ Variance of CONCEAL } & 1.703 & \multicolumn{3}{|l|}{0.044} & \multicolumn{2}{|c|}{1.352} & 0.076 & \\
\hline \multicolumn{2}{|c|}{ Covariance (DISCRIM, HOMONEG) } & 3.860 & \multicolumn{2}{|l|}{0.095} & 0.000 & \multicolumn{2}{|c|}{2.945} & 0.149 & 0.000 \\
\hline \multicolumn{2}{|c|}{ Covariance (CONCEAL, HOMONEG) } & 2.165 & \multicolumn{2}{|l|}{0.050} & 0.000 & \multicolumn{2}{|c|}{1.430} & 0.071 & 0.000 \\
\hline \multicolumn{2}{|c|}{ Covariance (CONCEAL, DISCRIM) } & 0.226 & \multicolumn{2}{|l|}{0.015} & 0.000 & & & 0.022 & 0.000 \\
\hline
\end{tabular}

$n_{\text {gays }}=48,160$ and $n_{\text {lesbians }}=12,240$

HOMONEG, DISCRIM and CONCEAL refer to latent variables homonegativity at work, discrimination at work and concealment at work 


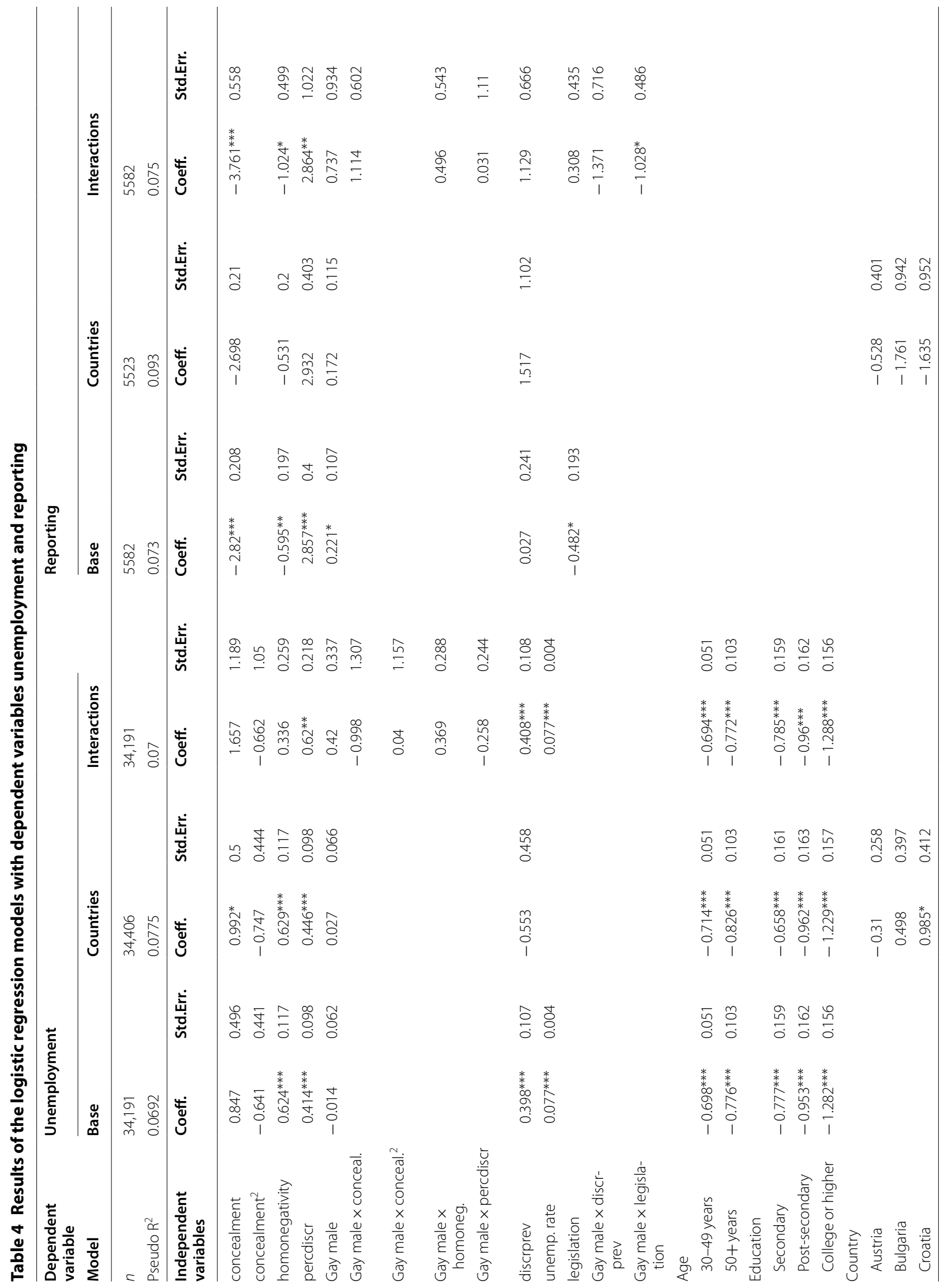




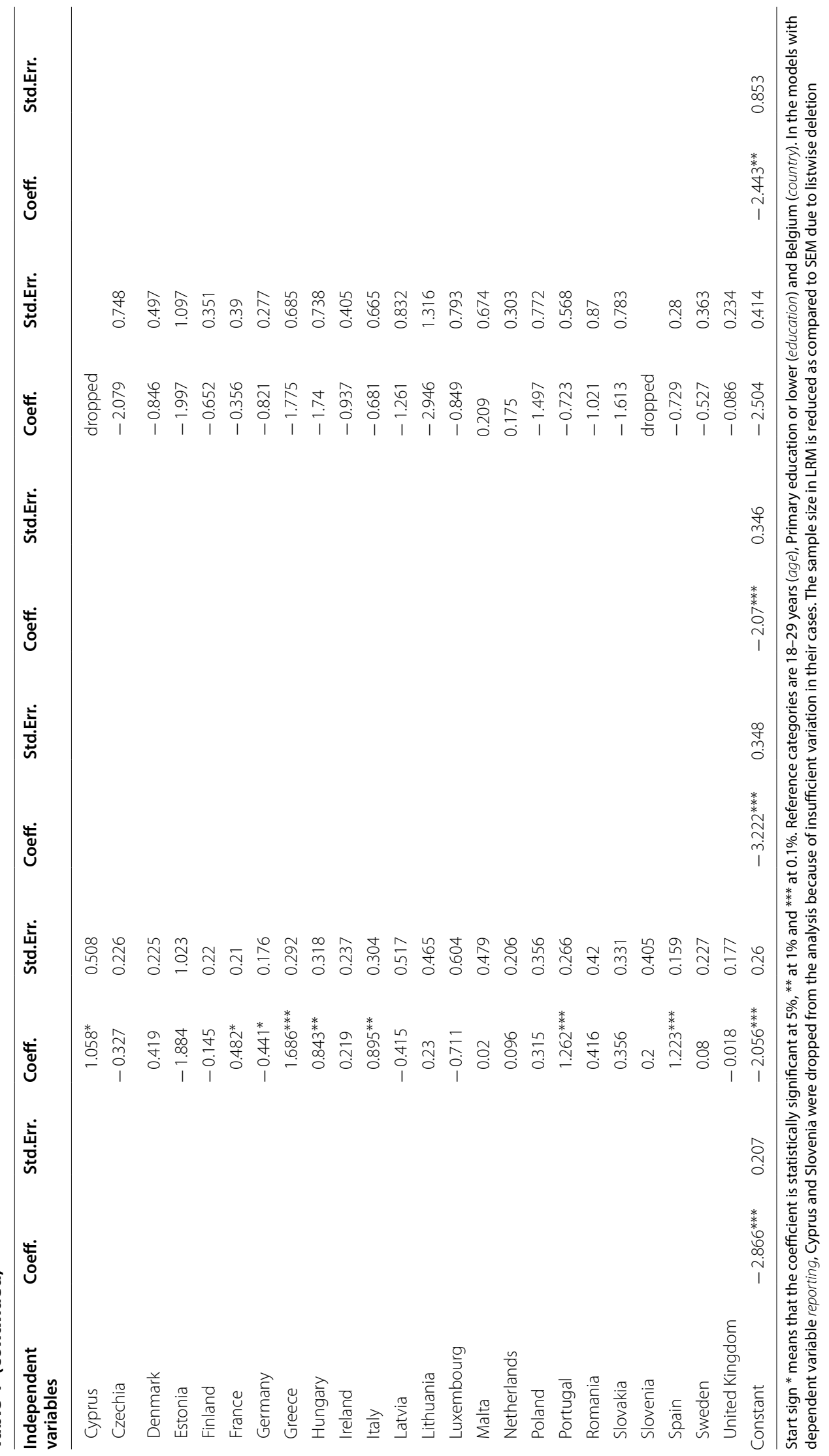


Received: 20 December 2017 Accepted: 24 October 2019

Published online: 11 November 2019

\section{References}

Arrow, K.: The theory of discrimination. Discrimination in labor markets. http:// www.econ.iastate.edu/classes/econ321/rosburg/Arrow-TheTheoryofDisc rimination.pdf (1973). Accessed 21 Mar 2015

Basow, S.A., Johnson, K.: Predictors of homophobia in female college students. Sex Roles 42(5/6), 391-404 (2000). https://doi.org/10.1023/A:1007098221 316

Bell, M.P., et al.: Introducing discriminatory job loss: antecedents, consequences, and complexities. J. Manag. Psychol. 28(6), 584-605 (2013). https://doi.org/10.1108/jmp-10-2012-0319

Brewer, G., Lyons, M.: Is gaydar affected by attitudes toward homosexuality? Confidence, labeling bias, and accuracy. J. Homosex. 64(9), 1241-1252 (2017). https://doi.org/10.1080/00918369.2016.1244443

Button, S.B.: Organizational efforts to affirm sexual diversity: a crosslevel examination. J. Appl. Psychol. 86(1), 17-28 (2001). https://doi. org/10.1037//0021-9010.86.1.17

Chaudoir, S.R., Fisher, J.D.: The disclosure processes model: understanding disclosure decision making and postdisclosure outcomes among people living with a concealable stigmatized identity. Psychol. Bull. 136(2), 236-256 (2010). https://doi.org/10.1037/a0018193

Chung, Y.B.: Work discrimination and coping strategies: conceptual frameworks for counseling lesbian, gay, and bisexual clients. Career Dev. Q. 50, 33-44 (2001)

Cotten-Huston, A.L., Waite, B.M.: Anti-homosexual attitudes in college students: predictors and classroom interventions. J Homosex. 38(3), 117-133 (2000). https://doi.org/10.1300/j082v38n03

Crandall, C., Eshleman, A.: A justification-suppression model of the expression and experience of prejudice. Psychol Bull (2003). https://doi. org/10.1037/0033-2909.129.3.414

De Vaus, D.A.: Research Design in Social Research. Sage Publications Ltd, London (2001)

Drydakis, N.: Sexual orientation and labour market outcomes. IZA World Labor (2014). https://doi.org/10.15185/izawol.111

Estrada, A.X., Weiss, D.J.: Attitudes of military personnel toward homosexuals. J. Homosex. 37(4), 83-97 (1999). https://doi.org/10.1300/j082v37n04_05

Eurofound: Working life experiences of LGBT people and initiatives to tackle discrimination. Dublin. https://www.eurofound.europa.eu/observatories/ eurwork/articles/working-conditions-labour-market-law-and-regulation /working-life-experiences-of-lgbt-people-and-initiatives-to-tackle-discr imination (2016)

Eurostat: Unemployment by sex and age_-annual average (variable une_rt_a). http://appsso.eurostat.ec.europa.eu/nui/show.do?wai=true\&datas et=une_rt_a (2017). Accessed 9 Jan 2017

Fasoli, F., et al.: Gay- and lesbian-sounding auditory cues elicit stereotyping and discrimination. Arch. Sex. Behav. 46(5), 1261-1277 (2017). https://doi. org/10.1007/s10508-017-0962-0

Finney, S., DiStefano, C.: Non-normal and categorical data in structural equation modeling. In: Structural equation modeling: a second course, pp. 269-314. Information Age Publishing, Greenwich (2006). http://books google.com/books?hl=nl\&|r=\&id=iEv0y1MZKjcC\&oi=fnd\&pg=PA269 $\& d q=$ structural +equation + model + normal+data\&ots $=5$ H8PPxQPu\&sig=r2YOCtgPwdEXPhLPJyvhxUyMH1E. Accessed 6 Feb 2017

FRA: EU LGBT survey Technical report: Methodology, online survey, questionnaire and sample. http://fra.europa.eu/en/publication/2013/eu-lgbtsurvey-technical-report (2013)

Freeman, J.B., et al.: Sexual orientation perception involves gendered facial cues. Pers. Soc. Psychol. Bull. 20, 1-14 (2010). https://doi. org/10.1177/0146167210378755

Fric, K.: Access to the labour market for gays and lesbians-research review. J. Gay Lesbian Soc. Serv. 29(4), 319-361 (2017). https://doi. org/10.1080/10538720.2017.1365671

Göçmen, I., Yılmaz, V.:'Exploring perceived discrimination among LGBT individuals in Turkey in education, employment, and health care: results of an online survey. J. Homosex. (2016). https://doi.org/10.1080/00918 369.2016 .1236598
Goffman, E.: Stigma: Notes on the Management of Spoiled Identity. Simon and Schuster (2009). http://books.google.com/books/about/Stigm a.html?id=zuMFXuTMAqAC\&pgis=1. Accessed 14 Oct 2014

Goldsmith, A.H., et al.: The labor supply consequences of perceptions of employer discrimination during search and on-the-job: Integrating neoclassical theory and cognitive dissonance. J. Econ. Psychol. 25(1), 15-39 (2004)

Habtegiorgis, A.E., Paradies, Y.: Utilising self-report data to measure racial discrimination in the labour market. Aust. J. Labour Econ. 16(1), 5 (2013)

Herek, G.: The psychology of sexual prejudice. Current directions in psychological science. http://cdp.sagepub.com/content/9/1/19.short (2000). Accessed 21 Mar 2015

Herek, G., Capitanio, J.: "Some of my best friends": intergroup contact, concealable stigma, and heterosexuals' attitudes toward gay men and lesbians. Pers. Soc. Psychol. Bull. http://psychology.ucdavis.edu/Rainb ow/html/Best_Friends_96_pre.pdf. Accessed 19 Mar 2015

Horvath, M., Ryan, A.M.: Antecedents and potential moderators of the relationship between attitudes and hiring discrimination on the basis of sexual orientation. Sex Roles 48(3-4), 115-130 (2003). https://doi. org/10.1023/A:1022499121222

ILGA Europe: ILGA-Europe Rainbow Index, May 2012. http://www.lga-europ e.org/rainboweurope/2012 (2012). Accessed 23 Jan 2017

International Labour Organization: Resolution concerning statistics of the economically active population, employment, unemployment and underemployment. http://www.lo.org/global/statistics-and-datab ases/standards-and-guidelines/guidelines-adopted-by-internatio nal-conferences-of-labour-statisticians/WCMS_087481/lang-en/index .htm (1982)

Johnson, K.L., et al.: Swagger, sway, and sexuality: judging sexual orientation from body motion and morphology. J. Pers. Soc. Psychol. 93(3), 321-334 (2007)

Jones, K.P., King, E.B.: Managing concealable stigmas at work: a review and multilevel model. J. Manag. 40(5), 1466-1494 (2013). https://doi. org/10.1177/0149206313515518

Kanfer, R., Wanberg, C.R., Kantrowitz, T.M.: Job search and reemployment: a personality-motivational analysis and meta-analytic review. J. Appl. Psychol. 86(5), 837-855 (2001)

Kite, M.E., Whitley, B.E.: Sex differences in attitudes toward homosexual persons, behaviors, and civil rights a meta-analysis. Pers. Soc. Psychol. Bull. 22(4), 336-353 (1996). https://doi.org/10.1177/0146167296224002

Laumann, E.O., et al.: The Social Organization of Sexuality: Sexual Practices in the United States. University of Chicago Press, Chicago (1994). https://doi. org/10.1136/bmj.310.6978.540

Leppel, K.: Labour force status and sexual orientation. Economica 76, 197-207 (2009). https://doi.org/10.1111/j.1468-0335.2007.00676.x/full

Levina, M., Waldo, C.R., Fitzgerald, L.F.: We're here, we're queer, we're on TV: The effects of visual media on heterosexuals' attitudes toward gay men and lesbians1. J. Appl. Soc. Psychol. 30(4), 738-758 (2000). https://doi. org/10.1111/j.1559-1816.2000.tb02821.x/full

Major, B., Kaiser, C.R.: Perceiving and claiming discrimination. Handbook of Employment Discrimination Research: Rights and Realities, pp. 285-299. Springer, New York (2008). https://doi.org/10.1007/978-0-387-09467-0 14

Milliken, F., Martins, L.: Searching for common threads: understanding the multiple effects of diversity in organizational groups. Acad. Manag. Rev. http:// amr.aom.org/content/21/2/402.short (1996). Accessed 21 Aug 2015

Pichler, S., Varma, A., Bruce, T.: Heterosexism in employment decisions: the role of job misfit. J. Appl. Soc. Psychol. 40(10), 2527-2555 (2010)

Ragins, B.R., Cornwell, J.M.: Pink triangles: antecedents and consequences of perceived workplace discrimination against gay and lesbian employees. J. Appl. Psychol. 86(6), 1244-1261 (2001)

Ragins, B., Singh, R., Cornwell, J.: Making the invisible visible: fear and disclosure of sexual orientation at work. J. Appl. Psychol. 92(4), 1103 (2007)

Robertson, R.E., et al.: Estimates of non-heterosexual prevalence: the roles of anonymity and privacy in survey methodology. Arch. Sex. Behav. 47(4), 1069-1084 (2017)

Rostosky, S.S., Riggle, E.D.B.: "Out" at work: the relation of actor and partner workplace policy and internalized homophobia to disclosure status. J Couns. Psychol. 49(4), 411-419 (2002). https://doi. org/10.1037//0022-0167.49.4.411 
Schneider, B:: Coming out at work: bridging the private/public gap. Work Occup. (1986). https://doi.org/10.1177/0730888486013004002

Skrondal, A., Rabe-Hesketh, S.: Structural equation modeling: categorical variables. Encycl. Stat. Behav. Sci. (2005). https://doi.org/10.1002/0470013192 .bsa596/full

Stangor, C., et al.: Ask, answer, and announce: three stages in perceiving and responding to discrimination. Eur. Rev. Soc. Psychol. 14, 277-311 (2003) https://doi.org/10.1080/10463280340000090

StataCorp LP: STATA Structural Equation Modeling Reference Manual, p. 575. A Stata Press Publication, College Station (2013) https://www.google.nl/ search?q=stat+sem + manual\&sourceid=ie7\&rls=com.microsoft:en-IE:IEAddress\&ie $=\& o e=\& g f e \_r d=c r \& e i=F F i T W N-f M o 7 H 8 A f H s o j o$ Ag. Accessed 2 Feb 2017

Tilcsik, A.: Pride and prejudice: employment discrimination against openly gay men in the United States. Am. J. Sociol. 117(2), 586-626 (2011). https:// doi.org/10.1086/661653
Valfort, M.-A.: LGBTI in OECD Countries. OECD Publishing (2017). https://doi. org/10.1787/d5d49711-en

van Balen, B., et al.: The situation of LGBT groups in the labour market in European Member States, report of the network of socio-economic experts in the field of anti-discrimination. http://ec.europa.eu/justice/discrimina tion/files/sen_synthesisreport2010parti_en.pdf (2011)

\section{Publisher's Note}

Springer Nature remains neutral with regard to jurisdictional claims in published maps and institutional affiliations.

\section{Submit your manuscript to a SpringerOpen ${ }^{\circ}$ journal and benefit from:}

- Convenient online submission

- Rigorous peer review

- Open access: articles freely available online

- High visibility within the field

- Retaining the copyright to your article

Submit your next manuscript at $\boldsymbol{\nabla}$ springeropen.com 